\title{
Avaliação microbiológica de agulhas sistêmicas descartáveis de acupuntura1
}

\section{Microbiological evaluation of disposable systemic acupuncture needles}

\section{Microbiológicos evaluación sistémica de las agujas desechables para la acupuntura}

Flaviana Regina Pimenta', Lara Stefania Netto de Oliveira Leão", Fabiana Cristina Pimenta"I

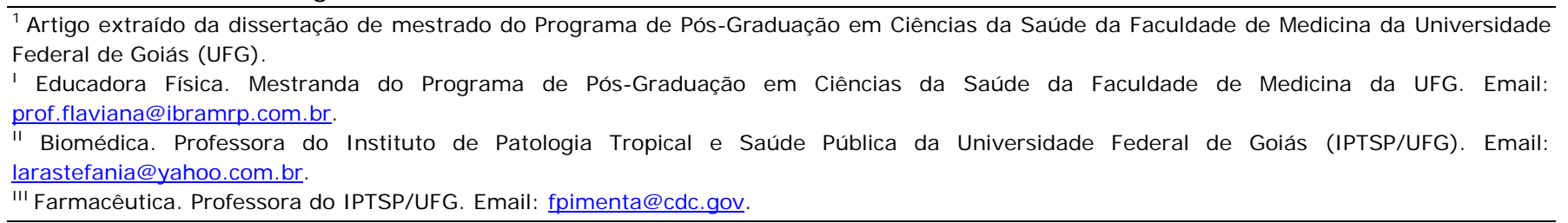

\section{RESUMO}

A acupuntura é uma técnica invasiva que tem como principal ferramenta o uso de agulhas. Este estudo teve como objetivo avaliar a qualidade microbiológica de diferentes marcas de agulhas sistêmicas descartáveis de acupuntura e identificar os microrganismos contaminantes isolados. Amostra foi composta por 11 marcas, correspondendo a 30 lotes diferentes, totalizando 1500 agulhas sistêmicas descartáveis de acupuntura analisadas em Goiânia no ano de 2007. Procedeu-se ao teste de esterilidade por meio de técnica asséptica, distribuindo as agulhas em tubo de ensaio contendo água peptonada, incubados à $37^{\circ} \mathrm{C}$ por 21 dias. As amostras com contaminação visível foram semeadas em placas de ágar sangue para o isolamento microbiano. As colônias desenvolvidas foram caracterizadas macro e microscopicamente (coloração de Gram) e, posteriormente, realizado testes bioquímicos para identificação das espécies isoladas. A contaminação microbiana foi detectada em $13(0,86 \%)$ das 1500 agulhas analisadas, pertencentes a seis marcas, sem alcançar, no entanto, significância estatística. Os microrganismos identificados foram bacilos Gram positivos, Micrococcus sp e estafilococos coagulase negativa. Verificou-se um número reduzido de agulhas contaminadas, sem significância estatística, portanto, essas marcas podem ser consideradas seguras para o uso nos procedimentos de acupuntura.

Descritores: Infecção; Exposição a agentes biológicos; Terapia por acupuntura; Acupuntura; Pontos de acupuntura.

\section{ABSTRACT}

The acupuncture is an invasive technique and the needles are the principal instrument. The objective of this study is to analyze the microbiological quality from different marks of disposable systemic acupuncture needles and to identify the contaminants microorganisms isolated. Study of 11 labels, corresponding to 30 different lots, a total of 1500 disposable systemic acupuncture needles were submitted to microbiological analyzed in Goiânia in 2007. The needles were inoculated in peptone water with aseptic techniques and incubated at $37 \circ \mathrm{C}$ for 21 days. The tubes with growth were streaked in blood agar to isolate the microorganism. The colonies were identified by Gram stain and biochemical tests. The microbiological contamination was detected in $13(0.86 \%)$ from the 1500 analyzed needles, corresponding to six labels, but the rate did not present any statistical significance. The microorganisms were identified as Gram positive bacilli, Micrococcus sp and negative coagulase staphylococci. The microbiological contamination rate did not present a statistical significance, and the analyzed needles should be considered security for using in acupuncture procedures.

Descriptors: Infection; Exposure to biological agents; Acupuncture therapy; Acupuncture; Acupuncture points.

\section{RESUMEN}

La acupuntura es una técnica invasiva que tiene como su principal herramienta el uso de agujas. Este estudio tuvo como objetivo evaluar la calidad microbiológica de las distintas marcas de agujas sistémicas desechables de acupuntura y identificar los microorganismos contaminantes aislados. La muestra fue compuesta por 11 marcas, que representan 30 lotes diferentes, con un total de 1500 agujas sistémicas desechables para la acupuntura analizada en Goiânia en él año de 2007. Esta fue la prueba de esterilidad a través de una técnica aséptica, la distribución de agujas en un tubo de ensayo que contenía agua de peptona, se incubarán a 37ํㅡ durante 21 días. Las muestras con contaminación visible se sembraron en placas de agar sangre para el aislamiento microbiano. Las colonias desarrolladas se caracterizaron macro y microscópicamente (tinción de Gram) y luego llevado a cabo pruebas bioquímicas para identificar las especies aisladas. La contaminación microbiana se detectó en $13(0,86 \%)$ de las 1500 agujas analizadas, pertenecientes a seis marcas, sin alcanzar, sin embargo, la significación estadística. Los microorganismos se identificaron Gram positivos, Micrococcus sp y estafilococos coagulasa negativos. Hubo un pequeño número de agujas contaminadas, sin significación estadística, por lo tanto, estas marcas pueden considerarse seguras para su uso en los procedimientos de acupuntura.

Descriptores: Infección; Exposición a agentes biológicos; Terapia por acupuntura; Acupuntura; Los puntos de acupuntura. 


\section{NTRODUÇÃO}

A acupuntura é uma técnica milenar de origem chinesa, recomendada pela Organização Mundial de Saúde (OMS) e incorporada pelo Sistema Único de Saúde (SUS), que emprega procedimentos predominantemente invasivos, que visam provocar estímulos em zonas neurorreativas de localização anatomicamente definida, denominadas pontos de acupuntura. A estimulação desses pontos provoca liberação de neurotransmissores e outras substâncias endógenas produzidas pelo organismo ${ }^{(1)}$. A acupuntura visa, com isso, restabelecer a circulação correta de energia nos órgãos e vísceras, levando todas as atividades e estruturas do organismo à uma harmonia de energia e matéria ${ }^{(2-3)}$.

Uma das principais ferramentas da acupuntura são as agulhas sistêmicas, definidas pelo Ministério da Saúde ${ }^{(1)}$ como instrumento filiforme perfurante, de ponta divulsionante, destinadas à penetração em pele, tecido subcutâneo e músculos. Assim sendo, as agulhas são reconhecidas como artigos críticos por penetrarem na pele e tecidos do paciente, devendo ser considerado seu risco potencial para carrear microrganismos causadores de infecções ${ }^{(4)}$. Cuidados especiais devem ser tomados na escolha da melhor agulha a ser utilizada, certificando-se da sua procedência, esterilização, embalagem e conservação antes do manuseio, evitando contaminações.

Apesar das agulhas serem consideradas artigos críticos, existem poucos relatos de casos de contaminação devido ao uso de agulhas de acupuntura, mostrando ser uma técnica segura e eficaz, na qual se recomenda o uso de materiais descartáveis, devidamente esterilizados e embalados ${ }^{(5-6)}$. Existe um consenso na literatura sobre os principais efeitos adversos nos procedimentos de acupuntura: tonturas e vertigens, hematoma local, pneumotórax, infecções locais, dermatite de contato, náuseas e vômitos, dor no local da introdução da agulha, mal-estar, traumas em órgãos, lesões em nervos, entre outros, sendo que muitos desses efeitos podem ser evitados pelo uso das normas de biossegurança e de uma adequada capacitação dos profissionais ${ }^{(6-12)}$.

Segundo Wash ${ }^{(13)}$ não há evidências de que um número significante de microrganismos possa ser transmitido pelos procedimentos de acupuntura, mas o controle de infecção é essencial. Existem relatos de transmissão de Staphylococcus aureus pelas agulhas de acupuntura ${ }^{(5,14)}$, bem como da transmissão de vírus como o da aids (HIV), e hepatites (HBV e HCV). Na maior parte destes casos, a transmissão se dá pela esterilização inadequada das agulhas reutilizáveis, o que enfatiza a recomendação do uso de agulhas sistêmicas descartáveis.

Após realizar uma revisão literária relacionada aos principais efeitos adversos da acupuntura, tendo como principal ênfase o controle de infecção, os pesquisadores Pimenta, Leão e Pimenta ${ }^{(15)}$ concluíram que a acupuntura é segura e eficaz, desde que as normas de biossegurança sejam seguidas, principalmente para evitar o risco de transmissão de microrganismos. A maior parte dos efeitos adversos encontrados na prática dessa terapia foram por falta de uso de material devidamente esterilizado e despreparo dos profissionais. Então, por ser uma técnica invasiva que usa agulhas como uma de suas principais ferramentas, recomenda-se sempre o uso de agulhas descartáveis de boa procedência.

Além do uso de materiais descartáveis, é necessário seguir as normas de precauções padrão no desempenho de todas as atividades da área da saúde de atendimento a pacientes, independente de suspeita ou não de doenças transmissíveis para prevenir a transmissão de microrganismos, pois essas medidas protegem o profissional e também previnem a transmissão cruzada entre pacientes ${ }^{(16)}$.

Por serem consideradas artigos críticos empregados em procedimentos invasivos, o presente estudo teve o objetivo de analisar a qualidade microbiológica de diferentes marcas de agulhas sistêmicas descartáveis de acupuntura, bem como identificar os microrganismos contaminantes isolados.

\section{MÉTODOS}

O estudo foi realizado no Laboratório de Bacteriologia Médica do Instituto de Patologia Tropical e Saúde Pública (IPTSP) da Universidade Federal de Goiás (UFG), na cidade de Goiânia no ano de 2007. A análise foi realizada com agulhas sistêmicas descartáveis de acupuntura adquiridas no comércio dos estados de Goiás, Minas Gerais e São Paulo e também na cidade de Xiamen - China.

Diferentes revendedores dos estados de Goiás, Minas Gerais e São Paulo foram visitados com o intuito de adquirir diferentes marcas e lotes de agulhas sistêmicas, mas os lotes disponíveis para aquisição eram os mesmos, pois os distribuidores/importadores desse tipo de material no Brasil são os mesmos e recebem grandes lotes e distribuem para todo país, o que impossibilitou analisar a mesma quantidade de lotes para cada marca de agulha. Foram encontradas apenas onze marcas diferentes de agulhas para análise. 


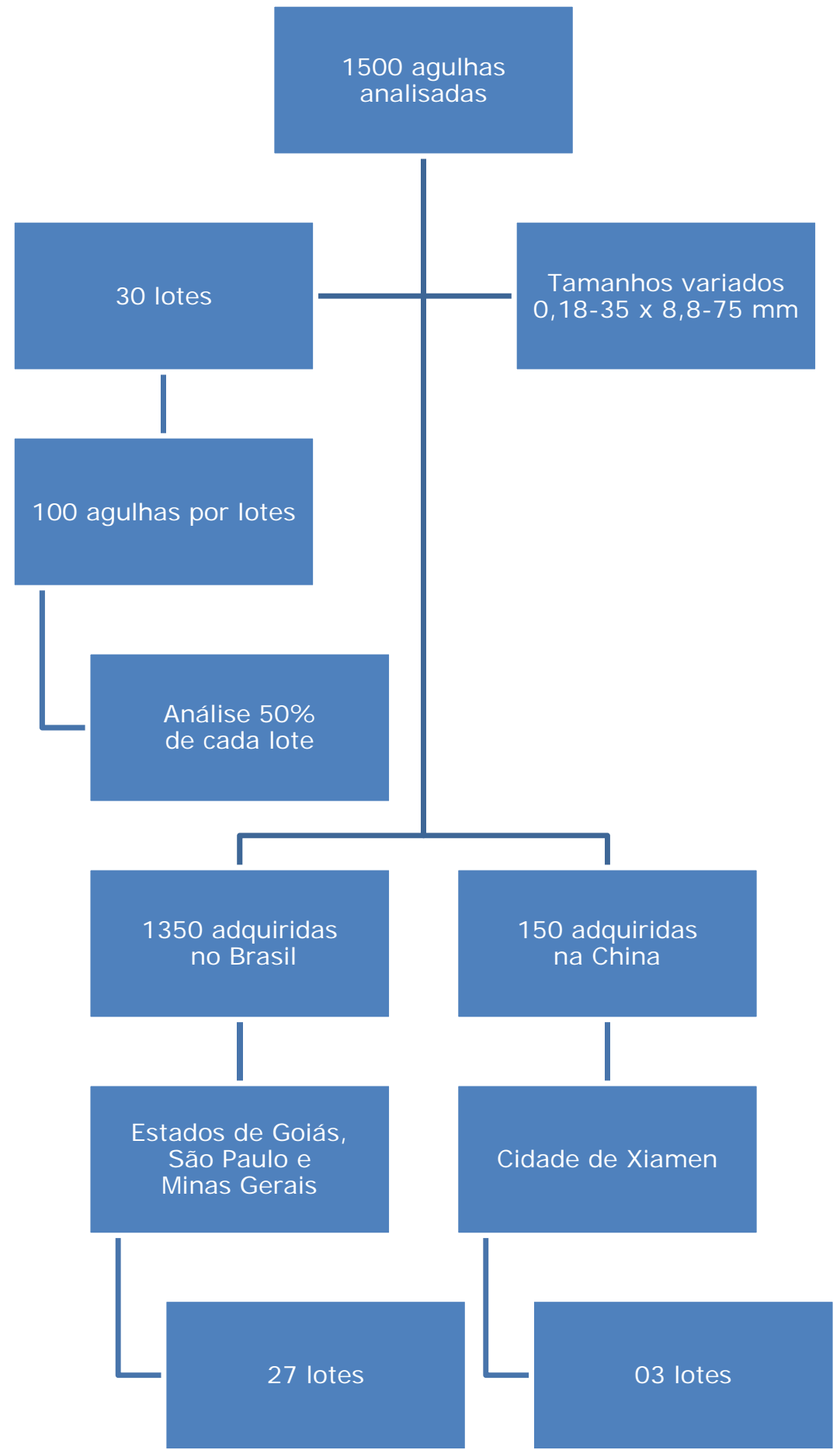

Figura 1: Tamanho da amostra de agulhas sistêmicas descartáveis de acupuntura e locais de aquisição (Goiânia, 2007).

Foram pesquisadas nove marcas de agulhas que estão em concordância com as normas do Ministério da Saúde (MS) do Brasil, a qual regulamenta e fiscaliza a comercialização desse produto. Além destas, foram avaliadas duas marcas de agulhas que não estão regulamentadas pelo $\mathrm{MS}$, sendo que o risco de estarem carreando microrganismos contaminantes pode ser maior devido a possível falta do seu controle de qualidade. Em geral, as agulhas sistêmicas descartáveis de acupuntura são comercializadas em embalagens com 100 unidades, podendo estar em caixas ou em sacos plásticos, com embalagens individuais, de 5 em 5, de 10 em 10 ou de 20 em 20 agulhas. Os tipos de embalagens variam de fabricante para fabricante sem critérios previamente estabelecidos. Os tamanhos e os diâmetros das agulhas também são variados conforme local anatômico de aplicação e função desejada.

O tamanho da amostra foi definido pela fórmula de cálculo para amostra finita, considerando $p=0,5$ da proporção por não ter valor de literatura, com nível de confiança de 95,0\% (valor crítico $z=1,96$ ) com margem de erro de $2,0 \%{ }^{(17)}$. A amostra foi 
composta por 11 marcas, correspondentes a 30 lotes diferentes, totalizando 1500 agulhas.

Foram anotadas informações sobre cada marca/lote de agulhas, com as especificações contidas na embalagem, envolvendo as seguintes características: marca, fabricante, país, importador/distribuidor, CNPJ, responsável, registro no MS, tipo de agulha, método de esterilização, tamanho, número do lote, data de fabricação, data de validade, tipo de embalagem, quantidade de agulhas, certificação do sistema de qualidade.

Para o teste de esterilidade, foram analisadas $50 \%$ do número total de cada lote de 100 agulhas sistêmicas descartáveis de acupuntura de tamanho variando de 0,18/35 × 0,8/75 milímetros $(\mathrm{mm})$. Das 1500 agulhas sistêmicas descartáveis analisadas, 1350 foram adquiridas no comércio no Brasil e 150 na China. Para a realização do teste de esterilidade dessas agulhas utilizou-se luvas esterilizadas, pinças esterilizadas envolvidas em papel grau cirúrgico e tubos de ensaio contendo caldo água peptonada ${ }^{(18)}$.

A distribuição da água peptonada nos tubos foi realizada conforme o tamanho da agulha sistêmica de acupuntura. Ou seja, o volume do caldo de cultura deveria cobrir totalmente a agulha e exceder por um centímetro, para evitar que no período de 21 dias de análise o cabo da agulha ficasse exposto pela possível evaporação.

Procedeu-se ao teste de esterilidade das agulhas sistêmicas por meio de técnica asséptica e a semeadura foi realizada em fluxo laminar, empregando técnica asséptica. Com o auxílio da pinça esterilizada a agulha foi retirada da embalagem e transferida para um tubo de ensaio contendo a água peptonada, os quais foram incubados à $37{ }^{\circ} \mathrm{C}$ por 21 dias, sendo observados diariamente para a detecção de sinais de multiplicação microbiana como turvação, produção de gás ou formação de depósito ${ }^{(18)}$. Foram utilizados tubos controle contendo apenas água peptonada quando da realização dos cultivos.

Para se evitar a interferência no resultado da análise das agulhas, a distribuição das amostras nos tubos de ensaio com água peptonada foi feita pelas mesmas pesquisadoras, bem como a identificação posterior dos microrganismos encontrados.

As amostras com contaminação visível, ou seja, turvação, produção de gás ou formação de depósito foram semeadas em placas de ágar sangue $(5 \%$ de sangue de carneiro) para o isolamento microbiano. As colônias desenvolvidas foram caracterizadas macro e microscopicamente (coloração de Gram) e, posteriormente, realizado testes bioquímicos para identificação das espécies isoladas ${ }^{(18)}$.

Os cocos Gram positivos foram inicialmente submetidos à prova da catalase e, em seguida, repicados em ágar manitol salgado e ágar sangue de carneiro para a observação de suas características coloniais (fermentação do manitol, perfil de hemólise e macroscopia das colônias). Os estafilococos também foram avaliados quanto à produção da enzima coagulase em tubo ${ }^{(18)}$.

Os bacilos Gram positivos foram avaliados quanto à produção da enzima catalase, urease e lecitinase; fermentação da glicose, sacarose, salicina, manitol, lactose e xilose; produção de indol e $\mathrm{H}_{2} \mathrm{~S}$; motilidade; perfil de hemólise em ágar sangue de carneiro à $5 \%$, hidrólise da esculina e observação de esporos em esfregaços submetidos à coloração de Wirtz-Conklin ${ }^{(18)}$.

Os laudos com os resultados de presença ou ausência microbiana foram enviados aos respectivos representantes/distribuidores e responsáveis técnicos das diferentes marcas de agulhas sistêmicas descartáveis de acupuntura analisadas.

A análise estatística foi realizada a partir de um banco de dados construído no programa EPI INFO, versão $3.2^{(19)}$. Foi definido como nível de significância igual a 0,05 para os testes univariados de associação. $\mathrm{Na}$ análise univariada, a associação com a variável dependente foi avaliada através do teste quiquadrado, com correção de Yates, e calculados os intervalos de confiança de $95 \%$ para os "odds-ratios".

\section{RESULTADOS E DISCUSSÃO}

Foram analisadas 1500 agulhas sistêmicas descartáveis de acupuntura, compreendendo 11 marcas distribuídas em 30 lotes (Tabela 1). Dessas, apenas 13 agulhas apresentaram contaminação $(0,86 \%)$, correspondentes a seis marcas diferentes e sete lotes (Figura 2). 
Tabela 1: Características e número de lote e de agulhas sistêmicas de acupuntura analisadas (Goiânia, 2007).

\begin{tabular}{cccccc}
\hline $\begin{array}{c}\text { Marca da } \\
\text { agulha }\end{array}$ & Fabricação & $\begin{array}{c}\text { Número de } \\
\text { lotes }\end{array}$ & I dentificação do lote & $\begin{array}{c}\text { Registro no } \\
\text { MS }\end{array}$ & $\begin{array}{c}\text { Número de } \\
\text { agulhas }\end{array}$ \\
\hline M1 & China & 06 & G1, G2, G3, G4, G5, G6 & sim & A \\
M2 & China & 03 & G7, G8, G9 & sim & 150 \\
M3 & Coréia & 04 & G10, G11, G12, G22 & sim & 200 \\
M4 & Coréia & 02 & G13, G14 & sim & 100 \\
M5 & Coréia & 05 & G15, G16, G28, G29, G30 & sim & 250 \\
M6 & China & 02 & G17, G18 & sim & 100 \\
M7 & China & 02 & G19, G20 & sim & 100 \\
M8 & China & 01 & G21 & sim & 50 \\
M9 & China & 01 & G23 & C & 150 \\
M10 & B & 03 & G24, G25, G26 & 50 \\
M11 & Coréia & 01 & G27 & & 50 \\
\hline
\end{tabular}

\section{Legenda:}

- M marca;

- G grupo:

- A dados estão em chinês, impossibilitando a tradução das informações;

- B informação não descrita na embalagem;

- C isenta de registro no MS (agulhas veterinárias).

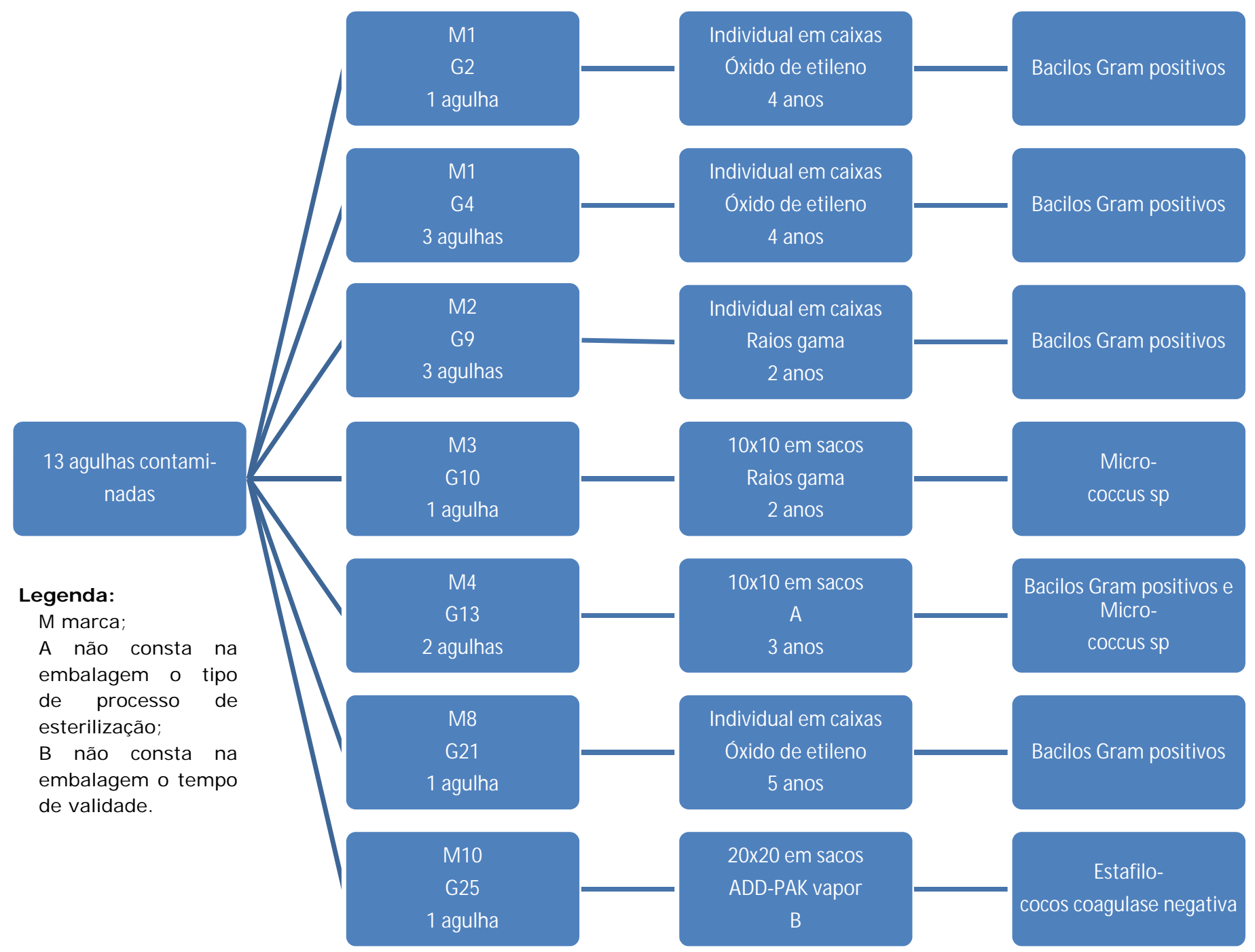

Figura 2: Resultados das análises das agulhas sistêmicas descartáveis de acupuntura (Goiânia, 2007). 
Com relação às características das 11 marcas de agulhas analisadas, algumas possuem o mesmo importador/distribuidor (seis marcas diferentes com três importadores/distribuidores), sendo a W.L. Comércio Importação e Exportação Ltda responsável pelas marcas 1 e 8, com fabricação na China; Xu Li Comércio, Importação e Exportação Ltda responsável por duas marcas, 3 e 5, ambas fabricadas na Coréia e também Mr. Ma Comércio Exportação e Importação Ltda, marcas 6 e 7, com fabricação chinesa. Quanto às agulhas chinesas, não foi possível obter os dados, pois as informações na embalagem estão em chinês, impossibilitando a tradução. Os outros importadores/distribuidores analisados são responsáveis por apenas uma marca encontrada no mercado. Das 11 marcas avaliadas, seis foram fabricadas na China e quatro na Coréia. O local de fabricação das agulhas da marca 10 não consta na embalagem, mas o seu distribuidor é da cidade de São Carlos, estado de São Paulo - Brasil (Tabela 1 e 2).

Tabela 2: Caracterização das agulhas sistêmicas quanto à marca, empacotamento, processo de esterilização e datas de fabricação/validade (Goiânia, 2007).

\begin{tabular}{|c|c|c|c|c|c|c|}
\hline Marca & Lote & $\begin{array}{c}\text { Tipo de } \\
\text { embalagem }\end{array}$ & $\begin{array}{l}\text { Processo de } \\
\text { esterilização }\end{array}$ & $\begin{array}{c}\text { Data de } \\
\text { fabricação }\end{array}$ & $\begin{array}{c}\text { Data de } \\
\text { Validade }\end{array}$ & $\begin{array}{c}\text { Validade em } \\
\text { anos }\end{array}$ \\
\hline M1 & G1 & 1 & $\mathrm{OE}$ & 20.12 .05 & 20.12 .09 & 4 \\
\hline M1 & G2 A & 1 & OE & 10.05 .05 & 10.05 .09 & 4 \\
\hline M1 & G3 & 1 & OE & 02.2003 & 02.2007 & 4 \\
\hline M1 & G4 A & 1 & OE & 20.03 .05 & 20.03 .09 & 4 \\
\hline M1 & G5 & 4 & $\mathrm{OE}$ & 10.10 .04 & 10.10 .08 & 4 \\
\hline M1 & G6 & 4 & OE & 20.08 .05 & 20.08 .09 & 4 \\
\hline M2 & G7 & 2 & RG & 01.04 .06 & 01.04 .08 & 2 \\
\hline M2 & G8 & 2 & RG & 15.06 .06 & 15.06 .08 & 2 \\
\hline M2 & G9 A & 1 & RG & 20.03 .06 & 20.03 .08 & 2 \\
\hline M3 & G10 A & 3 & RG & 08.11 .05 & 07.11 .07 & 2 \\
\hline M3 & G11 & 4 & $\mathrm{OE}$ & 08.11 .05 & 07.11 .07 & 2 \\
\hline M3 & G12 & 1 & OE & 25.10 .05 & 24.10 .10 & 5 \\
\hline M4 & G13 A & 4 & B & 31.10 .05 & 31.10 .08 & 3 \\
\hline M4 & G14 & 4 & B & 07.03 .05 & 07.03 .08 & 3 \\
\hline M5 & G15 & 4 & RG & 03.2003 & 03.2008 & 5 \\
\hline M5 & G16 & 4 & RG & 11.10 .05 & 11.10 .10 & 5 \\
\hline M6 & G17 & 1 & $\mathrm{OE}$ & 05.06 .06 & 06.2008 & 2 \\
\hline M6 & G18 & 1 & OE & 08.03 .06 & 03.2008 & 2 \\
\hline M7 & G19 & 3 & OE & 04.2006 & 04.2008 & 2 \\
\hline M7 & G20 & 3 & OE & 06.06 .06 & 06.2008 & 2 \\
\hline M8 & G21 A & 1 & OE & 16.06 .05 & 16.06 .10 & 5 \\
\hline M3 & G22 & 4 & RG & 26.09 .06 & 25.09 .11 & 5 \\
\hline M9 & G23 & 1 & OE & 10.06 .05 & 10.06 .08 & 3 \\
\hline M10 & G24 & 5 & ADD-PAKvapor & B & B & B \\
\hline M10 & G25 A & 5 & ADD-PAKvapor & B & B & B \\
\hline M10 & G26 & 5 & ADD-PAKvapor & B & B & B \\
\hline M11 & G27 & 6 & $\mathrm{~B}$ & B & ID & ID \\
\hline M5 & G28 & 4 & RG & 28.02 .06 & 28.02 .11 & 5 \\
\hline M5 & G29 & 4 & RG & 05.2003 & 05.2008 & 5 \\
\hline M5 & G30 & 4 & RG & 28.02 .06 & 28.02 .11 & 5 \\
\hline
\end{tabular}

Legenda:

- M: marca

- G: lote;

- A: lotes com detecção de agulhas contaminadas;

- B: informação não descrita na embalagem:

- 1: agulhas embaladas de forma individual e acondicionadas em caixas com 100 unidade

- 2: agulhas embaladas de 5 em 5 em sacos plásticos e acondicionadas em caixas com 100 unidades

- 3: agulhas embaladas de 10 em 10 em sacos plásticos e acondicionadas em caixas com 100 unidades;

- 4: agulhas embaladas de 10 em 10 em sacos plásticos e acondicionadas em outro saco plástico com 100 unidades;

- 5: agulhas embaladas de 20 em 20 em sacos plásticos e acondicionadas em outro saco plástico com 100 unidades;

- 6: embaladas de 10 em 10, acondicionadas sobre uma cartão de papelão e recobertas por plástico;

- OE: óxido de etileno;

- RG: raios gama;

- ID: validade indeterminada. 
Das dez marcas comercializadas no Brasil, nove possuem registro no Ministério da Saúde (MS). De acordo com a inscrição na embalagem, a marca 11 está isenta de registro no MS e corresponde ao lote G27, pois é utilizada em procedimentos veterinários. Das 11 marcas analisadas, somente as marcas 1 e 9 teem responsáveis e certificação no sistema de qualidade registrado na embalagem. As marcas 3, 6 e 8 possuem responsáveis, mas não consta a certificação no sistema de qualidade (Tabela 1 e 2).

As agulhas estavam acondicionadas em diferentes embalagens, sendo que em 10 lotes as agulhas eram embaladas de forma individual e acondicionadas em caixas com 100 unidades. Em dois lotes as agulhas estavam embaladas de cinco em cinco em sacos plásticos e em três lotes, embaladas de 10 em 10 em sacos plásticos e todas acondicionadas em caixas com 100. Em 11 lotes, as agulhas eram embaladas de 10 em 10 em sacos plásticos enquanto que em três lotes, as agulhas estavam embaladas de 20 em 20 em sacos plásticos e todas acondicionadas em outro saco plástico com
100 unidades. As agulhas do lote veterinário estavam embaladas de 10 em 10, acondicionadas sobre um cartão de papelão e recobertas por plástico (Tabela 2).

Três processos de esterilização das agulhas foram descritos: óxido de etileno em 14 lotes de agulhas, raios gama em 10 lotes e esterilização por ADD-PAK vapor em três lotes. Em três lotes não constava na embalagem qual foi o processo de esterilização usado (Tabela 2).

A contaminação microbiana foi detectada em 13 $(0,86 \%)$ das 1500 agulhas sistêmicas de acupuntura analisadas, pertencentes a seis marcas correspondendo a sete lotes, sem alcançar, no entanto, significância estatística. Os microrganismos identificados foram bacilos Gram positivos em 10 agulhas (cinco lotes de quatro marcas), Micrococcus $\mathrm{sp}$ em duas agulhas (dois lotes de duas marcas) e estafilococos coagulase negativa em uma agulha (um lote de uma marca), conforme apresentado na Tabela 3.

Tabela 3: Características microbiológicas das agulhas sistêmicas

descartáveis de acupuntura analisadas (Goiânia, 2007).

\begin{tabular}{cccc}
\hline Marca da agulha & Lote & Número de agulhas contaminadas & Microrganismo identificado \\
\hline M1 & G2 & 01 & Bacilos Gram positivos \\
M2 & G4 & 03 & Bacilos Gram positivos \\
M3 & G10 & 03 & Micrococcus sp \\
M4 & G13 & 01 & Bacilos Gram positivos \\
M5 & A & 02 & Micrococcus sp \\
M6 & A & 01 & A \\
M7 & A & A & A \\
M8 & G21 & A & B \\
M9 & A & A & Bacilos Gram positivos \\
M10 & G25 & 01 & Estafilococos coagulase negativa \\
M11 & A & A & A
\end{tabular}

Legenda:

- M marca;

- A não apresentaram contaminação.

Conforme pesquisado, as agulhas sistêmicas de acupuntura são artigos críticos e considerando seu risco potencial para carrear microrganismos, devem estar devidamente esterilizadas para uso para não causarem infecção ${ }^{(4,15,20)}$, não podendo dessa forma haver nenhum tipo de contaminação microbiana para sua aplicação nos pacientes.

Todas as agulhas analisadas foram fabricadas no período de 2003 a 2006, com vencimento de 2007 a 2011 e validade variando de dois a cinco anos. Em quatro lotes não estava informada a data de fabricação e validade e nem o número de anos, sendo que em um deles consta validade indeterminada, correspondente ao lote das agulhas veterinárias (G27) (Tabela 2). Na literatura consta que o prazo de validade deva ser estabelecido em cada produto, de acordo com as características da embalagem, método de selagem, manipulação e condições de estocagem. Somente em um dos lotes contaminados não constava a data de validade das agulhas (G25). A data de validade das agulhas deve ser observada rigorosamente, pois determina que aquela embalagem esteja dentro do prazo de esterilização previsto pelo fabricante, podendo ser usada de forma segura.

Não foi observada relação entre o tipo de embalagem e o processo de esterilização como fator determinante para o número de anos de validade de cada lote de agulhas sistêmicas descartáveis de acupuntura. Cada marca tem um período estipulado de validade de suas agulhas, independente da embalagem e do processo de esterilização. A marca 1 
tem um prazo de validade de quatro anos para suas agulhas; as marcas 3, 6, 7 e 2 de dois anos; marcas 4 e 9 com três anos de validade; e as marcas 5 e 8, período de cinco anos. Nas embalagens das marcas 10 e 11 não há descrição desse dado. Dos sete lotes com detecção de agulhas contaminadas, em quatro lotes (G2, G4, G9, G21) as agulhas estavam embaladas de forma individual e acondicionadas em caixas com 100 unidades. No lote $\mathrm{G} 10$ as agulhas eram embaladas de 10 em 10 em sacos plásticos e acondicionadas em caixas com 100 unidades. Nos lotes G13 e G25 as agulhas estavam embaladas de 10 em 10 e de 20 em 20 respectivamente, em sacos plásticos e acondicionadas em outro saco plástico com 100 unidades (Tabela 2).

Observou-se que o maior número de lotes contaminado (quatro lotes) era de agulhas embaladas individualmente e depois acondicionadas em caixas, correspondendo a oito das 13 agulhas contaminadas.

Desses sete lotes com agulhas contaminadas, três lotes eram com esterilização por óxido de etileno, dois lotes por raios gama, um lote por ADDPAK vapor e em somente um lote não foi descrito na embalagem qual o tipo do processo usado. Nesse estudo verificou-se que o tipo de embalagem e o tipo de esterilização não estavam relacionados com a qualidade microbiológica das agulhas analisadas.

Os microrganismos isolados (bacilos Gram postivos, Micrococcus sp e estafilococos coagulase negativa) estão amplamente distribuídos no ambiente e são encontrados como parte da microbiota normal da pele e mucosas de humanos e animais. Apesar de serem considerados microrganismos contaminantes, podem se comportar como patógenos oportunistas capazes de produzir doença em indivíduos debilitados. Os estafilococos coagulase negativa, em particular, vêm se destacando como importante agente de doenças humanas como bacteremias, endocardites e osteomielites, além da emergenciada resistência aos antimicrobianos habitualmente utilizados $^{(18)}$

Os estafilococos podem causar efeitos adversos severos, provocando várias infecções e problemas. Encontrou-se na literatura alguns casos de infecções associados a acupuntura causadas por Stphylococcus aureus $^{(5,14)}$, salientando, assim, a necessidade de procedimentos mais efetivos nos processos de esterilização dos materiais de acupuntura(15).

Apesar da taxa de contaminação microbiana $(0,86 \%)$ não alcançar, no entanto, significância estatística, a existência de contaminação indica falha nos processos de esterilização, armazenamento ou conservação das agulhas. Este fato se torna de grande relevância quando estas agulhas forem utilizadas em indivíduos imunocomprometidos e, portanto, vulneráveis às infecções.
Dos lotes com contaminação, não foi possível encontrar uma relação direta com os tipos de embalagens, processos de esterilização e prazo de validade, descartando essas características como fator determinante para a qualidade microbiológica das agulhas sistêmicas descartáveis de acupuntura, apesar de existir falha no processamento desses artigos pela presença de contaminação em algumas agulhas.

\section{CONCLUSÃO}

Em suma, das onze marcas analisadas, apenas 0,86\% (13 agulhas) do total das 1500 agulhas sistêmicas descartáveis de acupuntura apresentaram algum tipo de contaminação, pertencentes a seis marcas correspondentes a sete lotes, e por ser um número baixo de agulhas contaminadas, sem significância estatística, essas marcas são consideradas seguras para o uso nos procedimentos de acupuntura.

Apesar de seguras, os bacilos Gram postivos, Micrococcus sp e estafilococos coagulase negativa isolados das 13 agulhas são considerados contaminantes, quando em contato com os vários tecidos e corrente sanguínea dos pacientes pela inserção das agulhas, podendo causar várias infecções acarretando problemas graves.

\section{REFERÊNCIAS}

1. Ministério da Saúde. Política Nacional de Medicina Natural e Práticas Complementares PMNPC - junho de 2005. Brasília: Ministério da Saúde; 2005.

2. Yamamura Y. Acupuntura Tradicional: a arte de inserir. São Paulo: Roca; 2001.

3. Kaptchuk TJ. Acupuncture: theory, efficacy, and practice. Ann Intern Med. 2002; 136(5):374-83.

4. Center for Disease Control and Prevention (CDC). Guidelines for Infection Control in Dental Health Care Setting. MMWR Morb Mortal Wkly Rep [Internet]. 2003 [cited 2005 oct 10];52(RR17):1-61. Available from:

http://www.cdc.gov/mmwr/preview/mmwrhtml/rr521 7a1.htm.

5. Daivajna S, Jones A, O'Malley $M$, Mehdian $H$. Unilateral septic arthritis of a lumbar facet joint secondary to acupuncture treatment-a case report. Acupunct Med. 2004;22(3): 152-5.

6. White, A. A cumulative review of the range and incidence of significant adverse events associated with acupuncture. Acupunct Med. 2004;22(3):12233.

7. Vincent C. The safety of acupuncture. BMJ . 2001; 323: 467-8.

8. Yamashita $H$, Tsukayama $H$, White AR, Tanno $Y$, Sugishita C, Ernst E. Systematic review of adverse events following acupuncture: the Japanese literature. Complement Ther Med. 2001;9(2): 98-104. 
9. Ernst $G$, Strzyz $H$, Hagmeister $H$. Incidence of adverse effects during acupuncture therapy-a multicentre survey. Complement Ther Med. 2003; 1(2): 93-7.

10. Lao L, Hamilton GR, Fu J, Berman BM. Is acupuncture safe? A systematic review of case reports. Altern Ther Health Med. 2003; 9(1):72-83.

11. MaCPherson $H$, Scullion A, Thomas KJ, Walters $S$. Patient reports of adverse events associated with acupuncture treatment: a prospective national survey. Qual Saf Health Care. 2004; 13(5): 349-55.

12. Tanuseputro P, Yip G, Nolan L. Regulation of acupuncture and traditional chinese medicine in Ontorio. Univ Toronto Med J. 2007;84(3): 175-6.

13. Walsh B. Control of infection in acupuncture. Acupunct Med. 2001; 19(2): 109-11.

14. Chen $\mathrm{MH}$, Chen $\mathrm{MH}$, Huang J S. Cervical subdural empyema following acupuncture. J Clin Neurosci. 2004; 11(8): 909-11.

15. Pimenta FR, Leão LSNO, Pimenta FC. Controle de infecção: um requisito essencial na prática da acupuntura - revisão de literatura. Rev. Eletr. Enf. [Internet]. 2008 [cited 2009 jan 21]; 10(3):766-74. Available from: http://www.fen.ufg.br/revista/v10/n3/v10n3a22.htm 16. Cassetari VC, Balsamo AC, Silveira IR. Manual para prevenção das infecções hospitalares 2009. São Paulo: Hospital Universitário da Universidade de São Paulo; 2009.

17. Monteiro Filho G. Segredos da estatística em pesquisa científica. Goiânia: Vieira; 2004.

18. Koneman EW, Allen SD, Janda WM, Schreckenberger PC, Winn Jr WC. Diagnóstico microbiológico: texto e atlas colorido. São Paulo: Medsi; 2001. 1465 p.

19. Center for Disease Control and Prevention (CDC). Epi InfoTM [Internet]. 2004 [cited 2007 aug 02]. Available from: http://www.cdc.gov/nceh/ierh/ResearchandSurvey/M anual_ENA for_Epil nfo.pdf.

20. Graziano KU, Graziano RW. Limpeza, desinfecção e esterilização de artigos odontológicos e cuidados com o ambiente. In: Associação Paulista de Estudos e Controle de Infecção Hospitalar - APECIH. Controle de infecção na prática odontológica. São Paulo; 2000. p. 11-24.

Artigo recebido em 22.09.08

Aprovado para publicação em 08.06.09.

Artigo publicado em 30.09.09. 